\title{
Do They Get What They Want or Are They Stuck With What They Can Get? Testing Homophily Against Default Selection for Friendships of Highly Aggressive Boys. The TRAILS Study
}

\author{
Jelle J. Sijtsema • Siegwart M. Lindenberg • \\ René Veenstra \\ Published online: 25 March 2010 \\ (C) The Author(s) 2010. This article is published with open access at Springerlink.com
}

\begin{abstract}
In this study a homophily selection hypothesis was tested against a default selection hypothesis, to answer whether preferred and realized friendships of highly aggressive boys differed. In a large peer-nomination sample, we assessed who highly overt aggressive, low prosocial boys $(n=181)$ nominated as friends (preferred friendships) and who among the nominated friends reciprocated the friendship (realized friendships). These preferred and realized friendships were compared with those of less aggressive $(n=1,268)$ and highly aggressive but also prosocial boys (bi-strategics; $n=55$ ). Results showed that less aggressive boys preferred peers low on aggression, whereas highly aggressive and bi-strategic boys preferred peers not particular high or low on aggression. In line with default selection, highly aggressive boys ended up with aggressive peers even though that was not their preference. In general, received support proved an important determinant of highly aggressive, bi-strategic, and less aggressive boys' preferred and realized friendships. Especially highly aggressive boys preferred emotionally supportive friends, but ended up with the least supportive peers. In sum, for friendships of highly overt aggressive boys, the evidence favors default selection over homophily selection.
\end{abstract}

Keywords Aggression · Early adolescence · Friendship · Prosocial behavior

\footnotetext{
J. J. Sijtsema $(\triangle) \cdot$ S. M. Lindenberg $\cdot$ R. Veenstra Department of Sociology, University of Groningen, Grote Rozenstraat 31,

9712 TG Groningen, the Netherlands

e-mail: j.j.sijtsema@rug.nl

R. Veenstra

University of Turku,

Turku, Finland
}

\section{Introduction}

Intimate friendship relationships begin to develop especially in early adolescence (Berndt 1982) and are based on mutual attractiveness. However, if one is not able to establish such friendships, it can have serious negative developmental consequences in later life, leading to loneliness and depression (Nangle et al. 2003) and maladjustment (Bagwell et al. 1998). But how about friendships of highly overt aggressive boys? These boys have been shown to have aggressive peers as their best friends. In a study among 10 and 13 year-olds, highly aggressive boys were shown to have reciprocal friendships with similarly aggressive boys (Cairns et al. 1988). Moreover, in a study that assessed behavioral similarity between friends among third-graders, Poulin et al. (1997) showed that both direct observations and peer ratings indicated that friends in a play-group context were similar with respect to proactive aggression. But do highly aggressive boys really prefer aggressive friends? Their aggressiveness might scare off the potential friends they would prefer, creating great difficulties to realize the friendships they would like to have. Alternatively, aggressive peers may seek out each other as friends, and thus get what they want. To date, the vast majority of studies on peer relations and aggression has focused on the idea that adolescents select their friends according to their preferences. This hypothesis is based on the idea of homophily as a universal preference for friendships (Byrne 1971; McPherson et al. 2001). In terms of selection, friendship homophily refers to selection on the basis of similarity in behavior, opinions, or appearances. However, there is a contrasting hypothesis. The need for affection is likely to be universal (see Lindenberg 1996) and so even aggressive children who are not prosocial themselves may prefer friendships that 
include emotional warmth. However, due to their aggressive behavior, they might end up with friends among those nobody else wanted as friends because they lack warmth (Deptula and Cohen 2004; Hektner et al. 2000). In other words, friendship still occurs on the basis of similarity, but is due to a lack of availability instead of an actual preference for similarity. This phenomenon is called default selection. To date, little is known about the preferences of highly aggressive adolescent boys who are low on prosocial behavior. Who do they want as their friends? Do their preferred friendships differ from those they are able to realize? In this study we will focus on the preferred and realized friendships of highly overt aggressive, low prosocial early adolescent boys (from here on called: highly aggressive) and we will compare these to those of less or nonaggressive and highly aggressive-prosocial (i.e., bi-strategic) boys. To our knowledge, existing studies on friendships of early adolescents did not make a clear distinction between preferred (i.e., unilateral) and realized (i.e., reciprocal) friendships of aggressive boys. The question is: Do highly aggressive boys affiliate with similar peers because of homophily or default selection? Do they yearn for friendships with prosocial peers, like everybody else, or do they actively seek out other aggressive boys as friends?

\section{Friendship}

The importance of friendships in early adolescence has been shown in many studies. From childhood through adolescence, friendships become more salient (Buhrmester and Furman 1987; Marsh et al. 2006). Next to that, these relationships deepen, as children spend more time with their friends instead of their parents (Fallon and Bowles 1997; Larson et al. 1996), and the influence of friends becomes greater (Jang 1999). Along with the shift from relations with parents to establishing relationships with peers, adolescents generally derive emotional as well as practical support from their friends (Newcomb and Bagwell 1995; Stanton-Salazar and Spina 2005). What is the basis for forming friendships for highly aggressive boys? One of the leading ideas for friendship formation is homophily. Birds of a feather flock together (even if there are patterned differences as to what similarity dimensions are important, see Ham 2000). It has indeed been shown that befriended youth are often similar with regard to characteristics such as gender, background, and perceived interests (Berndt 1982; Hartup 1993; Tolson and Urberg 1993). In part, the similarity is the result of mutual influence rather than selection (in the sense of similarity preference). Thus, friends also become more similar over time. However, similarity based on selection has been shown to be a stronger factor in (early) adolescent friendships than similarity based on influence (see Urberg et al. 1998). Overtly aggressive friends in early adolescence are also quite similar, also with regard to aggressive behavior (Haselager et al. 1998; Poulin et al. 1997). Here too, selection effects have been found to be stronger than influence effects (Poulin and Boivin 2000). In addition, Cairns et al. (1988) have found that children who were identified as overtly aggressive by their teachers had many reciprocated friendships with other overtly aggressive peers, so homophily selection appears to govern friendship choice also for overtly aggressive youth. Lacking the ability to provide emotional support themselves, and being highly instrumental (Crick and Dodge 1996), they are likely to expect from friendship only instrumental, i.e., practical, support (for example support for being jointly aggressive towards others, see Grotpeter and Crick 1996). Thus, we hypothesize that: (a) highly aggressive boys prefer friends who are like them (high on overt aggression) and (b) they can realize the friendships they prefer to the same extent as their less aggressive counterparts. This is the homophily selection hypothesis. If we find evidence for this hypothesis, we can further examine the characteristics of the friendship relation in terms of perceived support (or benefits). In line with the homophily selection hypothesis we would expect that highly aggressive, nonprosocial boys will prefer non-supportive peers and that they can realize these friendships.

There is however another possibility. Highly aggressive boys may actually prefer friends who provide affection, referring to the combination of emotional and practical support that is so characteristic of friendship. It is unlikely that people have no need for affection (Lindenberg 1996; Ormel et al. 1997; Pendell 2002), even if they are highly aggressive and low on prosocial behavior themselves. For this reason, it is plausible to assume that highly aggressive boys do not get what they prefer when they select others who are overtly aggressive and lack the ability to give affection. A telltale sign might be that friendships of antisocial adolescents often dissolve quickly (Dishion et al. 1995). Although being overtly aggressive can contribute to popularity, it is unlikely to be attractive for friendship (Dijkstra et al. 2007; Hawley 2003; Newcomb et al. 1993). Overtly aggressive friends are known to be jointly aggressive towards others (Card and Hodges 2006), but they are also quick to respond with aggression towards their own friends when they feel provoked (Leary and Katz 2005). They also have been found to report significantly lower levels of friend intimacy than their nonaggressive counterparts (Grotpeter and Crick 1996). In short, what highly aggressive boys might want most out of friendships is the one thing they cannot provide: the combination of emotional and practical support. However, being unattractive as a friend, their own choice in friendships is quite limited. If they befriend other overtly aggressive peers, there is a good chance that they settle for second best. This 
leads to our second hypothesis that contrasts the homophily expectation: (a) highly aggressive boys prefer friends who are low on aggression, just like their less aggressive counterparts; and (b) they are less likely to realize their preferred kind of friendship than their less aggressive counterparts. This is the default selection hypothesis. That is, if the default selection hypothesis is supported, we expect that with regard to aggression there will be no difference between what highly aggressive and less aggressive boys prefer in their friendships. Moreover, we would also expect that highly aggressive boys prefer friends who are able to give emotional and practical support. In realized friendships however, we expect highly aggressive boys to have friends who are not only more aggressive than the friends of less aggressive boys, but also less supportive. There exists already some evidence for this hypothesis. For example, Aboud and Mendelson (1996) found that aggressive peers often lack alternatives for friendship formation. Moreover, Deptula and Cohen (2004) showed in their review that availability or default selection often leads rejected children to affiliate with each other, and the same may be true for highly aggressive adolescents. Also Hektner et al. (2000) showed that aggressive 7-year-old children had mutual friendships with similar peers, but revealed a preference for nonaggressive peers. Thus there are good reasons for each of the competing hypotheses.

In the following, we will test these competing hypotheses against each other. We do so by focusing on early adolescent boys who are high on overt aggression and low on prosocial behavior (also described as coercive controllers', see Hawley 2003). This way we could distinguish this group from bi-strategic boys, i.e., those who combine pro- and antisocial behaviors and who may thus also be attractive as friends for those who seek affection. As a validation, we compared the preferred and realized friendships of less aggressive boys with those of bi-strategic boys and expected that bi-strategic boys would want and end up with prosocial friends. That is, we hypothesized that the realized friends of bi-strategic and less aggressive boys were similar.

Although previous studies showed that antisocial and prosocial behavior can develop and be displayed differently for boys and girls (e.g., Hawley 2003; Van Lier et al. 2005; Wentzel et al. 2007), we were not able to test gender differences because there were too few highly overt aggressive girls in our sample. Therefore, we focused solely on boys in our analyses. In sum, we will compare friendship preferences and realized (i.e., reciprocal) friendships of highly aggressive, bi-strategic, and less aggressive early adolescent boys. Is there a difference in what they want? Is there a difference in what they can realize? We use the TRAILS study to answer these questions.

\section{Method}

Participants and Procedure

The TRacking Adolescents' Individual Lives Survey (TRAILS) is a prospective cohort study of Dutch preadolescents who will be measured biennially until they are at least 25 years old. The present study involves the second assessment wave of TRAILS, which started in 2003. TRAILS is designed to follow and explain the development of mental health and social development from preadolescence into adulthood. The TRAILS target sample was preadolescents living in five municipalities in the North of the Netherlands, including both urban and rural areas (De Winter et al. 2005). Of the target sample of 2,935 children, $76.0 \%$ were enrolled in the study, yielding $N=2,230$ (consent to participate: both child and parent agreed; mean age of child: 11.09, $S D=0.55$; gender: $50.8 \%$ girls; ethnicity: $10.3 \%$ children had at least one parent born in a non-western country; parent education: $32.6 \%$ of children had a father and 37.9 mother with a low educational level, at maximum a certificate from a lower track of secondary education). Of the 2,230 baseline participants, $96.4 \%$ participated in the second measurement wave, which was held two-and-a-half years after T1, at an average age of 13.5 years.

The sample used in this study was a subsample of TRAILS (Dijkstra et al. 2008). It involved only participants who were also included in the school-based peernominations data collection at $\mathrm{T} 2$, because we needed information from their friends. Peer nominations were assessed in classrooms with at least three regular TRAILS participants, leading to participation of a total of 172 classes in 34 schools in first (72 school classes) and second grade (100 school classes) of secondary education. Classrooms contained on average 18.39 participating students $(\mathrm{SD}=5.99$; range 7 to 30). In total, 1,007 regular TRAILS participants and 2,305 of their classmates (passive consent to participate) were involved in the peer nomination procedure. These 1,007 TRAILS participants did not differ from other TRAILS participants regarding gender, $\chi^{2}(1, N=2,149)=$ $1.17, p=0.28$, but were slightly younger (mean age 13.52 , $S D=0.51$, versus $13.60, S D=0.54), t(2,085)=3.49, p<0.001$, and had somewhat lower scores on aggressive behavior, $(M=-0.07, S D=0.88$ versus $M=0.07, S D=1.11), t(2,032)=$ $3.04, p=0.002$. The current study was only limited to boys and we had complete peer nomination information on 1,504 boys within 141 school classes, consisting of TRAILS participants and their classmates.

\section{Measures}

Preferred and Realized Friendships We opted for an indirect assessment by distinguishing preferences from 
actual friendship choices. We reasoned that if participants are asked to nominate best friends and if they can name as many as they like, they will name both peers whom they would like to be friends with (unilateral friends) and those with whom they actually are friends (reciprocal friends). Thus, we use unilateral friendship choices to indicate preferred friendships and reciprocal friendship choices to indicate realized friendships.

To assess preferred and realized friendship relations between adolescents and their peers, participants were asked 'which classmates are your best friends?' Respondents could provide unlimited nominations; that is, they could name as many best friends as there were peers in their classroom. Preferred and realized friendship were dichotomous variables $(0=$ no nomination; 1 = friendship nomination). Given that we dealt with an all-boys sample, nominations from and toward girls were excluded from the analyses. In total we analyzed 10,072 possible friendship nominations. Highly aggressive boys made 373 friendship nominations (2.06 on average), of which 142 were realized (38.1\%). Bi-strategic boys made 125 nominations (2.27 on average), of which 78 (62.4\%) were realized. Less aggressive boys made 2.31 friendship nominations on average. Of these 2,925 nominations, 1,391 were realized (47.6\%).

Overt Aggression We assessed overtly aggressive behavior by using peer nominations. Participants were asked 'who quarrels or fights a lot with other classmates?' We then calculated proportion scores for the peer nominations on aggressive behavior by dividing the number of nominations by the possible number of nominations. Subsequently, these scores were standardized over the whole sample.

Prosocial Behavior Prosocial behavior was also measured through peer nominations. Here, we distinguished between emotional support, assessed with 'which classmates help you when you are feeling down (e.g., problems at home)?', and practical support, assessed with 'which classmates help you with practical problems (e.g., completing homework, repairing a bike)?' Again, we calculated proportion scores for the peer nominations by dividing the number of nominations by the possible number of nominations. Scores of emotional and practical support $(r=0.49)$ were added up and standardized over the whole sample.

Perceived Benefits Using the directed peer nominations on emotional and practical support we determined perceived benefits of the friendship as a dichotomous variable. Perceived benefits were regarded as received emotional and practical support and thus inform us on who gives support to whom (support received $=1$, no support received $=0$ ).

Research Design In this study we created three groups: Highly aggressive, bi-strategic, and less aggressive boys.
First, we selected early adolescent boys from our sample who were high on overtly aggressive behavior and low on prosocial behavior, i.e., the highly aggressive boys. We selected those boys who were in the upper $10 \%$ on peerrated aggressive behavior. However, to make sure we were dealing with more or less "purely" aggressive boys and not with adolescents who were able to combine both pro- and antisocial behaviors, i.e., bi-strategic adolescents (e.g. Cairns et al. 1988; Newcomb et al. 1993), we selected only those who were below the mean on prosocial behaviors. Those aggressive boys who were above the mean on prosocial behaviors were labeled bi-strategic. Boys who scored in the lower $90 \%$ on aggression were labeled as less aggressive. Finally, we were left with 181 highly aggressive, 55 bi-strategic, and 1,268 less aggressive boys.

\section{Analytic Strategy}

First, we calculated descriptive statistics and correlations of all study variables for highly aggressive, bi-strategic, and less aggressive boys in preferred and realized friendships. To test our hypotheses, we conducted multilevel logistic regressions (using the Stata 10.0 SE package) to study the relation of aggressive and prosocial behavior with preferred and realized friendships. Multilevel analyses were conducted to control for the clustering of nominations within individuals, nested within different classrooms. Although we had no specific expectations regarding differences between school classes, we wanted to eliminate as much bias in nominations as possible due to differing classroom norms. Analyses were performed separately for preferred and realized friendship as the dependent variables. In both cases, friendship was a dichotomous variable, with a relationship being either present (coded 1) or absent (coded 0$)$. At the highest level we controlled for the school classes boys were in. At the second level we considered all nominations from one person dependent on each other. Thus, we considered all 'best friend' nominations coming from one person, to be nested in that person. At the lowest level, the friendship nominations themselves were analyzed.

For the multilevel logistic analyses we used a two-step approach. In the first step, we entered a dummy for comparing highly aggressive boys to less aggressive boys (i.e., the aggression dummy) and a dummy for comparing bi-strategic boys to less aggressive boys (i.e., the $b i$ strategic dummy). Furthermore, main effects were included for peers' aggressive and prosocial behavior and perceived benefits in terms of received emotional and practical support. In the second step, we included interactions with the highly aggressive and bi-strategic dummies, to test for differences between the (preferred and realized) friendships of highly aggressive, bi-strategic, and less aggressive boys. 
Table 1 Differences Between Preferred and Realized Friendships in Peer Characteristics and Perceived Benefits of Highly Aggressive, Bistrategic, and Less Aggressive Boys

\begin{tabular}{|c|c|c|c|c|c|c|c|c|c|c|c|c|}
\hline \multirow[b]{3}{*}{ Variable } & \multicolumn{6}{|c|}{ Preferred friendships } & \multicolumn{6}{|c|}{ Realized friendships } \\
\hline & \multicolumn{2}{|c|}{$\begin{array}{l}\text { Highly aggressive } \\
(n=181)\end{array}$} & \multicolumn{2}{|c|}{$\begin{array}{l}\text { Bi-strategic } \\
(n=55)\end{array}$} & \multicolumn{2}{|c|}{$\begin{array}{l}\text { Less aggressive } \\
(n=1,268)\end{array}$} & \multicolumn{2}{|c|}{$\begin{array}{l}\text { Highly aggressive } \\
(n=181)\end{array}$} & \multicolumn{2}{|c|}{$\begin{array}{l}\text { Bi-strategic } \\
(n=55)\end{array}$} & \multicolumn{2}{|c|}{$\begin{array}{l}\text { Less aggressive } \\
(n=1,268)\end{array}$} \\
\hline & Mean & S.E. & Mean & S.E. & Mean & S.E. & Mean & S.E. & Mean & S.E. & Mean & S.E. \\
\hline \multicolumn{13}{|l|}{ Peer Characteristics } \\
\hline Overt Aggression & 0.11 & 0.01 & 0.12 & 0.02 & 0.08 & 0.00 & $0.13^{\mathrm{a}}$ & 0.01 & 0.17 & 0.01 & 0.07 & 0.00 \\
\hline Prosocial Behavior & $0.16^{\mathrm{a}}$ & 0.01 & 0.18 & 0.01 & 0.17 & 0.00 & 0.14 & 0.01 & 0.20 & 0.01 & 0.17 & 0.00 \\
\hline \multicolumn{13}{|l|}{ Perceived Benefits } \\
\hline Emotional Support Received & 0.30 & 0.03 & 0.26 & 0.06 & 0.31 & 0.00 & $0.46^{\mathrm{a}}$ & 0.04 & $0.47^{\mathrm{a}}$ & 0.06 & $0.56^{\mathrm{a}}$ & 0.00 \\
\hline Practical Support Received & 0.39 & 0.03 & 0.32 & 0.07 & 0.48 & 0.01 & $0.62^{\mathrm{a}}$ & 0.04 & 0.42 & 0.06 & $0.68^{\mathrm{a}}$ & 0.01 \\
\hline
\end{tabular}

${ }^{\mathrm{a}}$ T-tests between preferred and realized friendships showed that the variable score was significantly higher $(p<0.05$, two-tailed tests) within aggression type

Effects of aggression and prosocial behavior on preferred and realized friendships are given in odds ratios. Odds ratios greater than one indicate a higher likelihood of being in a (preferred or realized) friendship, whereas odds ratios less than one indicate a lower likelihood.

\section{Results}

\section{Descriptive Analyses}

Unstandardized mean proportion scores and standard errors of preferred and realized friendships in highly aggressive, bi-strategic, and less aggressive boys are given in Table 1 . Mean comparisons between preferred and realized friendships showed that highly aggressive boys had significantly more overtly aggressive peers in realized friendships. Moreover, highly aggressive boys preferred prosocial peers, but realized significantly fewer friendships with these peers. However, within realized friendships highly aggressive boys received more support than in preferred friendships. Peer characteristics of bi-strategic and less aggressive boys did not differ between friendship types. Perceived benefits, however, showed that bi-strategic and less aggressive boys received more emotional support within realized friendships than in preferred friendships. Less aggressive boys furthermore received more practical support within realized friendships.

\section{Correlational Analyses}

Tables 2 and 3 provide correlations between the study variables for highly aggressive and less aggressive boys (Table 2) and bi-strategic boys (Table 3). Peer aggression correlated positively with realized friendships of highly aggressive boys, whereas peer aggression did not correlate with their preferred friendships. In less aggressive boys, aggression was slightly negative correlated to preferred friendships. Received emotional and practical support were more strongly correlated with realized friendships than with preferred friendships in both less aggressive and highly aggressive boys. Due to the smaller sample size of bistrategic boys (i.e., $n=55$ ) some expected associations did not reach significance. Interestingly, in bi-strategic boys received support was associated with realized friendships but not with preferred friendships. Moreover, peer aggres-

Table 2 Correlations Between Friendship, Aggression, and Prosocial Behavior (Highly Aggressive Boys [ $n=181]$ Below and Less Aggressive Boys $[n=1,268]$ Above the Diagonal)

\begin{tabular}{|c|c|c|c|c|c|c|}
\hline & 1 & 2 & 3 & 4 & 5 & 6 \\
\hline 1. Preferred Friendships & - & $-0.21 *$ & $-0.03 *$ & -0.02 & $0.15^{*}$ & $0.21 *$ \\
\hline 2. Realized Friendships & $-0.16^{*}$ & - & -0.02 & $-0.07 *$ & $0.43 *$ & $0.39 *$ \\
\hline 3. Peer Aggression & 0.03 & $0.19 *$ & - & $0.05 *$ & $-0.03 *$ & $-0.02 *$ \\
\hline 4. Peer Prosocial Behavior & -0.02 & -0.02 & $0.06^{*}$ & - & $-0.03 *$ & $-0.08^{*}$ \\
\hline 5. Emotional Support Received & $0.19 *$ & $0.30 *$ & $0.20 *$ & $-0.05^{*}$ & - & $0.50^{*}$ \\
\hline 6. Practical Support Received & $0.21 *$ & $0.35 *$ & $0.16^{*}$ & $-0.07 *$ & $0.37 *$ & - \\
\hline
\end{tabular}

${ }^{*} p<0.05$, two-tailed tests 
Table 3 Correlations Between Friendship, Aggression, and Prosocial Behavior of Bi-Strategic Boys $(n=55)$

\begin{tabular}{lccccc}
\hline & 1 & 2 & 3 & 4 & 5 \\
\hline 1. Preferred Friendships & - & & & & \\
2. Realized Friendships & $-0.24^{*}$ & - & & & \\
3. Peer Aggression & 0.09 & 0.10 & - & - & - \\
4. Peer Prosocial Behavior & -0.01 & -0.09 & -0.05 & -0.05 & -0.06 \\
5. Emotional Support Received & 0.06 & $0.40^{*}$ & $0.21^{*}$ & $-0.48^{*}$ \\
6. Practical Support Received & 0.08 & $0.25^{*}$ & & - \\
\hline
\end{tabular}

${ }^{*} p<0.05$, two-tailed tests

sion was positively associated with received support, indicating that bi-strategic boys had both aggressive peers and peers with perceived benefits.

\section{Multilevel Logistic Regressions}

Peer Aggression Although Tables 1 and 2 already indicated that highly aggressive boys differed in what friendships they prefer and realize, simple $t$-tests and correlations do not allow us to control for the nested structure of the data. Tables 4 and 5 therefore present the multilevel logistic regressions of respectively preferred and realized friendships. Random effects at the class and individual level showed that there was significant variation among classes and individuals regarding both preferred and realized friendships. On the basis of homophily selection we expected that highly aggressive boys preferred friends who are like them, whereas the default selection hypothesis stated that highly aggressive boys would prefer less aggressive friends. Interactions with the aggression dummy (Model 2) revealed that highly aggressive boys preferred peers not particularly high or low on aggression. Less

Table 4 Multilevel Logistic Regression Analyses of Ego, Peer, and Perceived Benefits on Preferred Friendships of Early Adolescent Boys

\begin{tabular}{|c|c|c|c|c|}
\hline & \multicolumn{2}{|l|}{ Model 1} & \multicolumn{2}{|l|}{ Model 2} \\
\hline & Odds ratio & $(95 \% \mathrm{CI})$ & Odds ratio & $(95 \% \mathrm{CI})$ \\
\hline \multicolumn{5}{|l|}{ Ego Characteristics } \\
\hline Aggression Dummy (1= yes) & 1.07 & $(0.81-1.41)$ & 1.02 & $(0.73-1.42)$ \\
\hline Bi-strategic Dummy $(1=$ yes $)$ & 0.68 & $(0.40-1.16)$ & 0.88 & $(0.47-1.63)$ \\
\hline \multicolumn{5}{|l|}{ Peer Characteristics } \\
\hline Overt Aggression & 0.93 & $(0.86-1.00)$ & $0.91 *$ & $(0.84-0.98)$ \\
\hline Prosocial Behavior & 0.96 & $(0.84-1.10)$ & 0.98 & $(0.85-1.13)$ \\
\hline \multicolumn{5}{|l|}{ Perceived Benefits } \\
\hline Emotional Support Received & $1.66^{* * *}$ & $(1.39-1.97)$ & $1.55 * * *$ & $(1.28-1.87)$ \\
\hline Practical Support Received & $3.34 * * *$ & $(2.83-3.93)$ & $3.49 * * *$ & $(2.92-4.17)$ \\
\hline \multicolumn{5}{|c|}{ Interactions with Aggression Dummy } \\
\hline Overt Aggression Peer & - & - & 1.10 & $(0.87-1.39)$ \\
\hline Prosocial Behavior Peer & - & - & 0.88 & $(0.57-1.36)$ \\
\hline Emotional Support Received & - & - & $1.72 *$ & $(1.00-2.95)$ \\
\hline Practical Support Received & - & - & 0.87 & $(0.54-1.43)$ \\
\hline \multicolumn{5}{|c|}{ Interactions with Bi-strategic Dummy } \\
\hline Overt Aggression Peer & - & - & 1.48 & $(0.95-2.32)$ \\
\hline Prosocial Behavior Peer & - & - & 0.93 & $(0.44-1.95)$ \\
\hline Emotional Support Received & - & - & 1.07 & $(0.38-2.99)$ \\
\hline Practical Support Received & - & - & 0.39 & $(0.14-1.08)$ \\
\hline Random Effects & Estimate & S.E. & Estimate & S.E. \\
\hline Class Level & $0.60 * * *$ & 0.07 & $0.60 * * *$ & 0.07 \\
\hline Individual Level & $1.17 * * *$ & 0.06 & $1.17 * * *$ & 0.07 \\
\hline
\end{tabular}

$* p<0.05 ; * * p<0.01 ; * * *<<0.001$ 
Table 5 Multilevel Logistic Regression Analyses of Ego, Peer, and Perceived Benefits on Realized Friendships of Early Adolescent Boys

\begin{tabular}{|c|c|c|c|c|}
\hline & \multicolumn{2}{|l|}{ Model 1} & \multicolumn{2}{|l|}{ Model 2} \\
\hline & Odds ratio & $(95 \% \mathrm{CI})$ & Odds ratio & $(95 \% \mathrm{CI})$ \\
\hline \multicolumn{5}{|l|}{ Ego Characteristics } \\
\hline Aggression Dummy ( $1=$ yes $)$ & $0.68 *$ & $(0.50-0.92)$ & 0.67 & $(0.44-1.03)$ \\
\hline Bi-strategic Dummy $(1=$ yes $)$ & $2.36^{* * *}$ & $(1.46-3.83)$ & $2.67 * *$ & $(1.48-4.82)$ \\
\hline \multicolumn{5}{|l|}{ Peer Characteristics } \\
\hline Overt Aggression & 1.03 & $(0.95-1.12)$ & 0.96 & $(0.88-1.05)$ \\
\hline Prosocial Behavior Peer & $0.72 * * *$ & $(0.62-0.85)$ & $0.72 * * *$ & $(0.61-0.86)$ \\
\hline \multicolumn{5}{|l|}{ Perceived Benefits } \\
\hline Emotional Support Received & $8.40 * * *$ & $(6.92-10.19)$ & $8.58 * * *$ & $(6.99-10.54)$ \\
\hline Practical Support Received & $7.45^{* * *}$ & $(6.16-9.02)$ & $7.40 * * *$ & $(6.04-9.07)$ \\
\hline \multicolumn{5}{|c|}{ Interactions with Aggressive Dummy } \\
\hline Overt Aggression Peer & - & - & $1.72 * * *$ & $(1.34-2.22)$ \\
\hline Prosocial Behavior Peer & - & - & 1.06 & $(0.61-1.85)$ \\
\hline Emotional Support Received & & & $0.54 *$ & $(0.30-0.97)$ \\
\hline Practical Support Received & - & - & 1.22 & $(0.71-2.10)$ \\
\hline \multicolumn{5}{|c|}{ Interactions with Bi-strategic Dummy } \\
\hline Overt Aggression Peer & - & - & 1.40 & $(0.93-2.12)$ \\
\hline Prosocial Behavior Peer & - & - & 0.76 & $(0.36-1.59)$ \\
\hline Emotional Support Received & - & - & 1.56 & $(0.66-3.69)$ \\
\hline Practical Support Received & - & - & 0.49 & $(0.20-1.20)$ \\
\hline Random Effects & Estimate & S.E. & Estimate & S.E. \\
\hline Class Level & $0.46^{* * *}$ & 0.08 & $0.46^{* * *}$ & 0.07 \\
\hline Individual Level & $1.11 * * *$ & 0.07 & $1.10 * * *$ & 0.07 \\
\hline
\end{tabular}

${ }^{*} p<0.05 ; * * p<0.01$

$* * * p<0.001$

aggressive boys showed a slight preference for peers who were low on overtly aggressive behavior $(\mathrm{OR}=0.91)$. Interactions with the bi-strategic dummy did not lead to significant interaction effects and thus indicated that their preferred friendships were similar to those of less aggressive boys.

With regard to realized friendships (see Table 5), multilevel logistic analysis first of all showed that being highly aggressive decreased $(\mathrm{OR}=0.68)$, whereas being bi-strategic $(\mathrm{OR}=2.36)$ increased, the likelihood of being in a realized friendship. Furthermore, based on homophily selection, we expected that highly aggressive and less aggressive boys could realize the friendships they preferred. In contrast, based on default selection we expected that highly aggressive, low prosocial boys could not realize their preferred friendships. Inclusion of the interactions with the aggression dummy (see Model 2), showed that highly aggressive boys were more likely to be in a realized friendship with other highly aggressive peers $(\mathrm{OR}=1.65)$ than less aggressive boys $(\mathrm{OR}=0.96)$. Again, bi-strategic boys did not differ significantly from less aggressive boys in their realized friendships in terms of peers' aggressive behavior.
Peer Prosocial Behavior and Perceived Benefits Additionally, we tested homophily versus default selection by looking at prosocial behavior and the perceived benefits (i.e., received practical and emotional support). Logistic regressions (see Table 4) showed no difference in preference regarding peer's prosocial behavior (i.e., the combination of emotional and practical support) for highly aggressive versus less aggressive boys within the friendship dyad. For bi-strategic versus less aggressive boys we also found no difference in preference for prosocial behavior. However, with regard to perceived benefits, preferred friendships were more likely when there was emotional and practical support within the friendship dyad (OR's 1.66 and 3.34, respectively). Looking at the interaction with the aggression dummy (see Model 2), we found that highly aggressive boys had a greater preference for peers from whom they received emotional support $(\mathrm{OR}=2.66)$. Results for realized friendships are presented in Table 5. Here, Model 1 shows that receiving emotional and practical support greatly increased the likelihood of being in a realized friendship ( $\mathrm{OR}=8.40$ and 7.45 , respectively) even though peer prosocial behavior was associated with a 
decreasing likelihood of being in realized friendships. Yet, there was a substantial difference between highly aggressive boys and the rest. Interactions with the aggression dummy showed that the likelihood of receiving emotional support in friendships was significantly lower for highly aggressive boys compared to less aggressive boys $(\mathrm{OR}=$ 4.63 versus $\mathrm{OR}=8.58$ ). Thus, highly aggressive boys were not able to realize their preference with regard to the perceived benefits of their friendship to the same extent as less aggressive and bi-strategic boys.

\section{Discussion}

In the literature on adolescent friendships and aggression there has been support for both the homophily selection and the default selection hypothesis. However, to date, studies have not tested these two hypotheses against each other. By assessing preferred and realized friendships in a large sample of early adolescent boys we found evidence mostly in favor of the default selection hypothesis. By making a clear distinction between two types of highly overt aggressive adolescents (low prosocial and prosocial bistrategic) on the one hand versus less or non-aggressive adolescents on the other hand, we showed that boys, whether highly aggressive or not, had fairly similar friendship preferences. Contradicting the homophily selection hypothesis, highly aggressive boys did not have a preference for similar aggressive peers but, in line with the default selection hypothesis, they failed to realize the preference they had. That is, they ended up with highly aggressive peers even though they would have preferred less aggressive peers. Less or non-aggressive boys however, preferred less aggressive friends and ended up with peers not particularly high or low on aggression. Bistrategic boys had no preferences regarding aggression and also ended up with peers who were neither high nor low on aggression. Additional support for the default selection hypothesis comes from looking at supportive behavior. In terms of what they want, aggressive, bistrategic, and non-aggressive boys did not differ. All boys nominated friends who they perceived as giving emotional and practical support. In fact, highly aggressive, low prosocial boys had a greater preference for emotionally supportive peers than less aggressive boys. Yet, with regard to realized (i.e., reciprocal) friendships, we found that friendship preferences of highly aggressive boys did not match their realized friendships. Realized friendships of highly aggressive boys were characterized by less emotional support than realized friendships of less aggressive boys. The findings for aggressive and supportive behavior are in line with Aboud and Mendelson (1996) who reasoned that aggressive boys may lack alternatives for reciprocal friendships and have to settle for less preferred friends.

For highly aggressive boys there seems to be an interesting consolation for the inability to realize their preferred friendships. They perceive to get emotional support from those who they nominate as friends, even though these peers do not reciprocate the friendship nomination. This could indicate that there is more than wishful thinking involved and that highly aggressive boys actually are able to realize some of their friendship preferences as a half-way house: Some emotional support without the others' acknowledgement of friendship. From another perspective, it may be that there are some boys who are nice and supportive to all their peers, irrespective of their level of aggression. Nonetheless, in the long run it can be expected that even these prosocial boys may stop being nice if aggression is directed toward them or if they receive no support in return. Related to this, for future research it would be worthwhile to study what comes first: support (emotional or practical) or friendship? Obviously, answering such a question would require longitudinal data.

Overall, our findings showed us four things. First, highly aggressive boys (i.e., high on aggression and low on prosocial behavior) preferred affectionate peers like everybody else. Second, previous studies mostly characterized the affiliation of two peers on the basis of similar characteristics as an active selection process. That is, peers are thought to choose each other on the basis of the homophily principle (see McPherson et al. 2001). Whereas this may still be true for most youth, we have shown that what in fact occurs among highly aggressive adolescent boys seems more like a process of default selection; they want the same kind of friends as all the others, but they do not get them and are therefore befriended with those who others do not care to choose. This way, they end up with more aggressive friends than the rest. Third, even though highly aggressive boys do not realize their preferred friendships, they do seem to be able to get some emotional support from those who do not call themselves their friends. Fourth, as Hawley et al. (2007) recently found, adolescents who successfully combine aggressive antisocial and prosocial behaviors may actually be the ones with many and healthy friendship. Our study found some support for this, in that bi-strategic boys did not differ from less aggressive boys and in fact had the highest percentage of realized friendships. This is related to Hawley's (1999) work, where she argued that youth who are able to combine aggressiveness with prosocial behavior actually gain more access to resources. It might thus be that it is not being high on aggression that creates default selection, but the lack of prosocial behavior. 
Strengths and Limitations

To the best of our knowledge, testing homophily against default selection for highly aggressive low prosocial boys has not been done before. There are more strong points of this study. Some previous contributions have also studied friendships of highly aggressive youth (e.g., Adams et al. 2005; Cairns et al. 1988), but they did not focus on the extreme end of the spectrum: those highly aggressive youth who are also low on prosocial traits. In contrast to these other studies, we used a large sample in which we were able to select this very specific group of highly aggressive and low prosocial boys. Moreover, we used peer-reported aggression which is less likely to be biased than teacher, self, or parent reports. Although we used only one item to measure overt aggression, this item was based on the average score of all classroom nominations on the question of 'who quarrels or fights a lot with other classmates?', thus making it a strong measure of overt aggression. Finally, we did not limit the number of friendship choices. This way it was more likely that participants not only nominated the friends that they actually had, but also the ones they would prefer. This indirect assessment of preferred and realized friendships is less sensitive to social desirability than a direct assessment (see e.g., Grotpeter and Crick 1996).

Our study also has some limitations. First, the crosssectional nature of our study is a limitation because it did not allow us to study the friendship selection process itself. Another limitation is that we were only able to study friendship choices inside the classroom. Kiesner et al. (2003) have shown that it can be important to include outside school friends as well. It could be that in another context (e.g., sports club or neighborhood) aggressive boys fit in better and have more realized friendships. Aggression may be maladaptive in schools, but on the sports field for instance, it can be seen as an asset. Friendship selection outside the school context may therefore be based on different aspects. Related to this, it may be that the emotional support that highly aggressive boys want from their friends is provided by peers outside the school context. Next to that, the number of prospects for friendships may be narrower in other contexts, which could impact friendship selection (e.g., in neighborhoods there might be relatively few same-aged peers around). Moreover, it may also be that highly aggressive, low prosocial boys are not so good at establishing the friendships they want but instead seek to be part of a bigger peer group or clique. This way, highly aggressive, low prosocial boys would not have close friendships but could still benefit from peer group support.

Another limitation concerns the gendered nature of overt aggression. Because we were only interested in overt aggression, we had to limit our analyses to aggressive boys, given the lack of overtly aggressive girls. However, it would be good to address possible gender differences in future research by also looking at different forms of aggression. That is, aggression is a heterogeneous construct and is not solely limited to its overt form. In the current study we only looked at overt aggression because relational aggression proves to be an ambiguous measure in the light of this study. In contrast to overt aggression, relational aggression is also associated with peer acceptance and has been linked to adaptive instead of maladaptive outcomes (Heilbron and Prinstein 2008). Given that relational aggression may at least in part be associated with positive outcomes (e.g., popularity), it may lead to different results when looking at preferred and realized friendships. Finally, the assessment of preferred friendships was not optimal. We did not directly ask respondents which friends they preferred, but assessed this only indirectly through unilateral best friendship nominations. However, given that respondents nominated between 1 and 16 peers as their best friends, it seems plausible to assume that part of these nominations are actually not 'best friends' but indicate a certain 'wanting to be best friends' with the nominated peer. This method is also strengthened by Hektner et al. (2000) who showed that both directly asking children's peer preferences and the assessment of unilateral and reciprocal friendships led to similar results.

\section{Future Directions of Research}

Future research may want to study whether highly aggressive youth also turn against their own friends (see Leary and Katz 2005), or whether they only behave aggressively toward non-friends, as found by Card and Hodges (2006). Furthermore, it would be interesting to see what negative results default selection may have for the social development of highly aggressive adolescents. As we have shown, highly aggressive boys had realized friendships mainly with overtly aggressive peers. Longitudinally, we would get more insight in the default selection process by testing whether default selection indeed precedes the development of more severe aggressive behaviors through mutual influence. Highly aggressive youth are likely to lack certain social skills, such as empathy and perspective taking, which enable social goal pursuit (Wentzel et al. 2007). A lack of social intelligence and empathy has also been linked to a physically aggressive style of conflict resolution (Björkqvist et al. 2000). Default selection may exacerbate this handicap because as aggressive youth become friends with other aggressive, less supportive, and less socially skilled peers, they come even more into contact with aggressive behavioral styles. As aggressive friends entice peers more to rule violating behavior (see 
Bagwell and Coie 2004), this can give rise to more behavioral maladjustment, which in turn decreases the chance of friendships with less or non-aggressive peers. That is, default selection may help push highly aggressive youth into a vicious cycle. In their review regarding deviant and delinquent behavior, Gifford-Smith et al. (2005) also showed that current interventions often segregate high-risk youth, instead of integrating them with prosocial youth. Because of default selection, it may be advisable for interventions to keep encouraging interactions between highly aggressive and less or non-aggressive adolescents. Empirical evidence for the beneficial effects of such an integration is provided by Adams et al. (2005) who showed that having low aggressive friends led to a decrease in aggression of highly aggressive youth in the course of 6 months. Moreover, teaming up aggressive boys with nonaggressive boys during a six-week summer school program, led to a decrease in aggressive behavior regardless of whether the two boys were buddies (Hektner et al. 2003). Such interventions would profit from the knowledge that highly aggressive low prosocial boys actually want prosocial friendships like everybody else. What they probably lack are prosocial skills that would help them realize their friendship preferences (Nangle et al. 2002).

Acknowledgements This research is part of the TRacking Adolescents' Individual Lives Survey (TRAILS). Participating centers of TRAILS include various departments of the University Medical Center and University of Groningen, the Erasmus University Medical Center Rotterdam, the University of Utrecht, the Radboud Medical Center Nijmegen, and the Parnassia Bavo group, all in the Netherlands. TRAILS has been financially supported by various grants from the Netherlands Organization for Scientific Research NWO (Medical Research Council program grant GB-MW 940-38011; ZonMW Brainpower grant 100-001-004; ZonMw Risk Behavior and Dependence grants 60-60600-98-018 and 60-60600-97-118; ZonMw Culture and Health grant 261-98-710; Social Sciences Council medium-sized investment grants GB-MaGW 480-01-006 and GB-MaGW 480-07-001; Social Sciences Council project grants GB-MaGW 457-03-018, GB-MaGW 452-04-314, and GB-MaGW 452-06-004; NWO large-sized investment grant 175.010.2003.005); the Sophia Foundation for Medical Research (projects 301 and 393), the Dutch Ministry of Justice (WODC), the European Science Foundation (EuroSTRESS project FP-006), and the participating universities. We are grateful to all adolescents, their parents and teachers who participated in this research and to everyone who worked on this project and made it possible. Moreover, we want to thank the editor and the anonymous reviewers as well as the members of the weekly discussion group WALM for their comments and suggestions on earlier versions of this article.

Open Access This article is distributed under the terms of the Creative Commons Attribution Noncommercial License which permits any noncommercial use, distribution, and reproduction in any medium, provided the original author(s) and source are credited.

\section{References}

Aboud, F. E., \& Mendelson, M. J. (1996). Determinants of friendship selection and quality: developmental perspectives. In W. M. Bukowski, A. F. Newcomb, \& W. Hartup (Eds.), The company they keep: Friendship in childhood and adolescence (pp. 87112). Cambridge: Cambridge University Press.

Adams, R. E., Bukowski, W. M., \& Bagwell, C. L. (2005). Stability of aggression during early adolescence as moderated by reciprocated friendship status and friend's aggression. International Journal of Behavioral Development, 29, 139-145.

Bagwell, C. L., \& Coie, J. D. (2004). The best friendships of aggressive boys: relationship quality, conflict management, and rule-breaking behavior. Journal of Experimental Child Psychology, $88,5-24$.

Bagwell, C. L., Newcomb, A. F., \& Bukowski, W. M. (1998). Preadolescent friendship and peer rejection as predictors of adult adjustment. Child Development, 69, 140-153.

Berndt, T. J. (1982). The features and effects of friendship in early adolescence. Child Development, 53, 1447-1460.

Björkqvist, K., Österman, K., \& Kaukiainen, A. (2000). Social intelligence - empathy = Aggression? Aggression and Violent Behavior, 5, 191-200.

Buhrmester, D., \& Furman, W. (1987). The development of companionship and intimacy. Child Development, 58, 1101-1113.

Byrne, B. (1971). The attraction paradigm. New York: Academic.

Cairns, R. B., Cairns, B. D., Neckermann, H. J., Gest, S. D., \& Gariépy, J. L. (1988). Social networks and aggressive-behaviorPeer support or peer rejection. Developmental Psychology, 24, $815-823$.

Card, N. A., \& Hodges, E. V. E. (2006). Shared targets for aggression by early adolescent friends. Developmental Psychology, 42, 1327-1328.

Crick, N. R., \& Dodge, K. A. (1996). Social information-processing mechanisms in reactive and proactive aggression. Child Development, 67, 993-1002.

Deptula, D. P., \& Cohen, R. (2004). Aggressive, rejected, and delinquent children and adolescents: a comparison of their friendships. Aggression and Violent Behavior, 9, 75-104.

De Winter, A. F., Oldehinkel, A. J., Veenstra, R., Brunnekreef, J. A., Verhulst, F. C., \& Ormel, J. (2005). Evaluation of non-response in mental health determinants and outcomes in a large sample of pre-adolescents. European Journal of Epidemiology, 20, 173181.

Dijkstra, J. K., Lindenberg, S., \& Veenstra, R. (2007). Same-gender and cross-gender peer acceptance and peer rejection and their relation to bullying and helping among preadolescents. Developmental Psychology, 43, 1377-1389.

Dijkstra, J. K., Lindenberg, S., \& Veenstra, R. (2008). Beyond the class norm: bullying behavior of popular adolescents and its relation to peer acceptance and rejection. Journal of Abnormal Child Psychology, 36, 1289-1299.

Dishion, T. J., Andrews, D. W., \& Crosby, L. (1995). Antisocial boys and their friends in early adolescence: relationship characteristics, quality, and interactional process. Child Development, 66, 151.

Fallon, B. J., \& Bowles, T. V. (1997). The effect of family structure and family functioning on adolescents' perceptions of intimate time spent with parents, siblings, and peers. Journal of Youth and Adolescence, 26, 25-43.

Gifford-Smith, M., Dodge, K. A., Dishion, T. J., \& McCord, J. (2005). Peer influence in children and adolescents: crossing the bridge 
from developmental to intervention science. Journal of Abnormal Child Psychology, 33, 255-265.

Grotpeter, J. K., \& Crick, N. R. (1996). Relational aggression, overt aggression, and friendship. Child Development, 67, 2328-2338.

Ham, J. V. (2000). Do birds of a feather flock together? The variable bases for African American, Asian American, and European American adolescents' selection of similar friends. Developmental Psychology, 36, 209-219.

Hartup, W. (1993). Adolescents and their friends. In B. Laursen (Ed.), Close friendships during adolescence: New directions for child development (pp. 3-22). San Francisco: Jossey-Bass.

Haselager, G. J., Hartup, W., Van Lieshout, C. F. M., \& RiksenWalraven, J. M. A. (1998). Similarities between friends and nonfriends in middle childhood. Child Development, 69, 11981208.

Hawley, P. H. (1999). The ontogenesis of social dominance: a strategy-based evolutionary perspective. Developmental Review, 19, 97-132.

Hawley, P. H. (2003). Prosocial and coercive configurations of resource control in early adolescence: a case for the welladapted Machiavellian. Merrill-Palmer Quarterly, 49, 279-309.

Hawley, P. H., Little, T. D., \& Card, N. A. (2007). The allure of a mean friend: relationship quality and processes of aggressive adolescents with prosocial skills. International Journal of Behavioral Development, 31, 170-180.

Heilbron, N., \& Prinstein, M. (2008). A review and reconceptualization of social aggression: adaptive and maladaptive correlates. Clinical Child and Family Psychology Review, 11, 176-217.

Hektner, J. M., August, G. J., \& Realmuto, G. M. (2000). Patterns of temporal changes in peer affiliation among aggressive and nonaggressive children participating in a summer school program. Journal of Clinical Child Psychology, 29, 603-614.

Hektner, J. M., August, G. J., \& Realmuto, G. M. (2003). Effects of pairing aggressive and nonaggressive children in strategic peer affiliation. Journal of Abnormal Child Psychology, 31, 399412 .

Jang, S. J. (1999). Age-varying effects of family, school, and peers on delinquency: a multilevel modeling test of interactional theory. Criminology, 37, 643-685.

Kiesner, J., Poulin, F., \& Nicotra, E. (2003). Peer relations across contexts: individual-network homophily and network inclusion in and after school. Child Development, 74, 1328-1343.

Larson, R. W., Richards, M. H., Moneta, G., Holmbeck, G., \& Duckett, E. (1996). Changes in adolescents' daily interactions with their families from ages 10 to 18: disengagement and transformation. Developmental Psychology, 32, 744-754.

Leary, A., \& Katz, L. F. (2005). Observations of aggressive children during peer provocation and with a best friend. Developmental Psychology, 41, 124-134.

Lindenberg, S. (1996). Continuities in the theory of social production functions. In H. Ganzeboom \& S. Lindenberg (Eds.), Verklarende Sociologie. Opstellen voor Reinhard Wippler (pp. 169-184). Amsterdam: Thesis.
Marsh, P., Allen, J. P., Ho, M., Porter, M., \& McFarland, F. C. (2006). The changing nature of adolescent friendships: longitudinal links with early adolescent ego development. Journal of Early Adolescence, 26, 414-431.

McPherson, M., Smith-Lovin, L., \& Cook, J. M. (2001). Birds of a feather: homophily and social networks. Annual Review of Sociology, 27, 415-444.

Nangle, D. W., Erdley, C. A., Carpenter, E. M., \& Newman, J. E. (2002). Social skills training as a treatment for aggressive children and adolescents: a developmental-clinical integration. Aggression and Violent Behavior, 7, 169-199.

Nangle, D. W., Erdley, C. A., Newman, J. E., Mason, C. A., \& Carpenter, E. M. (2003). Popularity, friendship quantity, and friendship quality: interactive influences on children's loneliness and depression. Journal of Clinical Child and Adolescent Psychology, 32, 546-555.

Newcomb, A. F., \& Bagwell, C. L. (1995). Children's friendship relations: a meta-analytic review. Psychological Bulletin, 117, 306-347.

Newcomb, A. F., Bukowski, W. M., \& Pattee, L. (1993). Children's peer relations: a meta-analytic review of popular, rejected, neglected, controversial, and average sociometric status. Psychological Bulletin, 113, 99-128.

Ormel, J., Lindenberg, S., Steverink, N., \& Vonkorff, M. (1997). Quality of life and social production functions: a framework for understanding health effects. Social Science and Medicine, 45, 1051-1063.

Pendell, S. D. (2002). Affection in interpersonal relationships: not just "a fond or tender feeling". Communication Yearbook, 26, 70 115.

Poulin, F., \& Boivin, M. (2000). The role of proactive and reactive aggression in the formation and development of boys friendships. Developmental Psychology, 36, 233-240.

Poulin, F., Cillessen, A. H. N., Hubbard, J. A., Coie, J. D., Dodge, K. A., \& Schwartz, D. (1997). Children's friends and behavioral similarity in two social contexts. Social Development, 6, 224-236.

Stanton-Salazar, R. D., \& Spina, S. U. (2005). Adolescent peer networks as a context for social and emotional support. Youth \& Society, 36, 379-417.

Tolson, J. M., \& Urberg, K. A. (1993). Similarity between adolescent best friends. Journal of Adolescent Research, 8, 274-288.

Urberg, K. A., Degirmencioglu, S. M., \& Tolson, J. M. (1998). Adolescent friendship selection and termination: the role of similarity. Journal of Social and Personal Relationships, 15, 703-710.

Van Lier, P. A. C., Vitaro, F., Wanner, B., Vuijk, P., \& Crijnen, A. A. M. (2005). Gender differences in developmental links among antisocial behavior, friends' antisocial behavior, and peer rejection in childhood: results from two cultures. Child Development, 76, 841-855.

Wentzel, K. R., Filisetti, L., \& Looney, L. (2007). Adolescent prosocial behavior: the role of self-processed and contextual cues. Child Development, 78, 895-910. 